\title{
DEVELOPMENT ULTRA-HIGH STRENGTH CEMENTITIOUS CHARACTERISTICS USING SUPPLEMENTARY CEMENTITIOUS MATERIALS*
}

\author{
Ameer Baiee*,** ORCID ID: 0000-0001-5393-7022 \\ Babylon University, Babylon, Iraq \\ *Corresponding author: Ameer Baiee, eng.ameer.tuama@uobabylon.edu.iq \\ ${ }^{* *}$ According to the author's PhD thesis, University of Brighton, research.brighton.ac.uk
}

Received: 06. 22. 2021

Accepted: 08. 12. 2021

\begin{abstract}
For sustainability purposes, supplementary cementitious materials (SCMs) are considered essential components for gaining ultra-high strength properties of concrete and mortar. This study experimentally investigates the influence of single, binary, and ternary partial cement replacements of the SCMs on the performance of ultra-high-strength mortar. The investigated SCMs were included ground granulated blast furnace slag (GGBS), densified silica fume (DSF), un-densified silica fume (UDSF), and Fly ash (FA). Three replacements ratios were implemented; $10 \%, 20 \%$, and $30 \%$ in addition to mortar without SCMs to work as a control mix for comparison reasons. 27 mixes were designed to quantify the replacement ratio that explains the best performance, through examining the workability, compressive and tensile strength of each mix. In addition, XRD test was carried out to identify the various decomposition phases of the hardened mortar. The results indicated that binary replacement of $15 \%$ GGBS and $15 \%$ UDSF exhibited the best performance among all other replacements ratios.
\end{abstract}

Keywords: binary replacement, ssupplementary cementitious materials, single replacement, ternary replacement, ultra-high strength, XRD patterns.

\section{Introduction}

Currently, there is a growing demand for high-strength cementitious materials in the field of structural constructions. Production such as these materials involves a high amount of cement which leading to resource consumptions and increases carbon dioxide emissions. Ernst Worrell et al. (2001) [1] stated that the production of one ton of cement releases about one ton of carbon dioxide. Moreover, in many cases, it might be a challenging to obtain a cementitious matrix with high-performance properties without incorporation SCMs.

The role of the SCMs in enhancing the strength mainly attributes to their pozzolanic reaction with the calcium hydroxide $\left(\mathrm{Ca}(\mathrm{OH})_{2}\right)$ that resulted from cement hydration to produce supplementary calcium-silicate-hydrate (C-S-H) gel which is the source of the strength [2]. Generally, many studies reported that the addition of SCMs significantly improves the mechanical properties of cementitious materials. However, the improvement depends on the type, properties, and replacements configuration [3 - 9]. 
GGBS is a waste by-product of steel industries, which has similar chemical and physical properties to Portland cement. Using GGBS in the field of concrete production leads to improve the strength and durability through pore refinement as a result of the pozzolanic reaction. Many studies investigated high replacement of GGBS, more than $50 \%$ by weight of cement, for concrete and mortar [6, 10 - 15]. However, it was found that higher than $20 \%$ of GGBS might adversely affect the strength of the cementitious matrix despite the enhancement in workability and durability. That could be attributed to the low development strength in early ages due to the insufficient amount of calcium hydroxide $\left(\mathrm{Ca}(\mathrm{OH})_{2}\right)$ that resulted from cement hydration $[12,16,17]$.

Silica fume is also a waste by-product of the production of silicon metal or silicon alloys. It contains a high amount of silicon dioxide $\left(\mathrm{SiO}_{2}\right)$ in an amorphous phase. Numerous researchers indicated the effectiveness of silica fume in enhancing the mechanical properties of concrete and mortar [3, 5, 7, 19, 11, 22]. Otherwise, it was reported that silica fume as a partial replacement of cement increases the water demand that significantly reduces the workability $[3,5,6,8,11]$. Most researchers confirmed the effectiveness of silica fume in the pore refinement in the hardened structure of concrete, which reduces the permeability and controls the volumetric changes $[18,20]$. Other studies found a slight enhancement in the drying shrinkage behavior of matrices with silica fume [3, 20]. The most productive replacement ratio of silica fume was ranged between 5 and 10 percent of cement $[5,6,10$, 19, 21, 23 - 26].

Similarly, the effectiveness of fly ash in enhancing the workability and durability of concrete and mortar was stated by many studies [8, 18, 28, 30]. However, other studies indicated adversely influences on the mechanical properties due to the low content of amorphous $\mathrm{SiO}_{2}$ in the composition of $\mathrm{FA}[7,10,11,20,27,28]$. The binary replacements of silica fume and fly ash were examined to gain high strength without reducing the workability [7, 27, 20, 29]. The obtained enhancement was limited within cementitious matrices that have normal strength. Additionally, some studies found a drop in strength due to the presence of FA compared with matrices with a single replacement of silica fume [7, 10]. Also, it was reported that binary replacement of silica fume with GGBS improves the performance of cementitious matrix especially for durability aspects $[6,11,20]$. On other hand, the GGBS was found less effective in enhancing the cementitious matrix that contains FA [20,29].

In the same field, ternary replacements of GGBS, SF and FA were observed improving the workability and strength of the cementitious matrix as reported by Rashad et al. 2014 [29]. It was found that addition 10 percent replacement of SF and GGBS to concrete contains FA exhibited higher improvement in strength compared with binary replacement of GGBS or SF with FA. Similarly, Dave et al. 2017 [30] found that the ternary replacement of 30\% of FA, $10 \%$ of SF and $10 \%$ of GGBS explained the highest improving in strength to about $16 \%$ compared with control. It can be stated that most of the previous investigations of the replacement of supplementary materials (SCMs) were conducted on cementitious materials with normal strength properties. However, limited studies concerning high-strength properties were conducted. Moreover, there are controversial data about the influences of SCMs on the performance of concrete and mortar. Therefore, the main objective of this study aims to investigate the effect of different amounts and configurations of the SCMs on the performance of ultra-high-strength cementitious materials. This investigation is part of comprehensive study of a PhD study at Brighton University for developing cementitious materials with ultra-high strength properties. 


\section{Experimental program}

\subsection{Materials}

In all investigated mixes, high strength cement type CEM 52.5N was used for casting the high strength mortar. Table 1 demonstrates the physical and chemical properties provided by the manufacturer (Hanson UK Company). Ground-granulated blast-furnace slag (GGBS) satisfying BS EN 15167-1:2006 [31] obtained from Hanson Heidelberg Cement group was utilized. The chemical compositions and physical properties of GGBS are listed in Table 1 (as supplied by the manufacturer). X-ray analysis of the GGBS demonstrates a high peak of $\mathrm{SiO}_{2}$ at $2 \theta$ equal to $21^{\circ}$. However, the peak had less intensity comparing the silica fume peak, which indicates a lower content of $\mathrm{SiO}_{2}$ in $\mathrm{GGBS}$ mineral content, as shown in Figure 1. In addition, no frequent peaks were observed that state an amorphous phase [32]. The chemical composition and physical properties of the densified (DSF) and un-densified silica fume (UDSF) obtained from the manufacturer (Elkem A Bluestar Company) are presented in Table 1. The X-ray patterns of a powder of both type of silica fume explained a peek at $2 \theta$ equal to $22^{\circ}$, which refers to a high characteristic of amorphous $\mathrm{SiO}_{2}$ [22], as shown in Figure 1. Fly ash type 450-S satisfying BS EN 450-1:2012 [33] was adopted in the mixes of highstrength mortar. This class of fly ash was used because of its high pozzolanic activity, and it has a constant fineness and carbon content. It was supplied from the Drax Power Station, North Yorkshire, UK under the CEMEX brand. The chemical and physical properties of the FA are listed in Table 1 . The X-ray diffraction analysis of fly ash (Figure 1) explained that the most crystalline constituents of the fly ash are quartz $\left(\mathrm{SiO}_{2}\right)$ at $2 \theta$ equal to $26^{\circ}$. However, the amorphous $\mathrm{SiO}_{2}$ appeared at $2 \theta$ of $21^{\circ}$ at less intensity.

Fine silica sand satisfying BS EN 12620:2002+A: 2008 [34] obtained from Sibelco UK was utilized in casting all investigated mixes. It contains a high proportion of silica in quartz configuration with a colour of yellow/brown. The grain distribution ranges between 0.5 to 0.1 $\mathrm{mm}$. Table 1 lists the chemical composition of silica sand (as supplied by the manufacturer). To achieve the desired workability, Fosroc Auracast 200 high-performance concrete superplasticizer based on polycarboxylate polymers (obtained from Resapol UK company) was used. It has a pH of $4+/-1$ with a specific gravity of $1.050-1.070$.

\section{Table 1}

The chemical and physical properties of cement, SCMs, and silica sand

\begin{tabular}{lccccc}
\hline Characteristics & CEM52.5N & Silica fume & GGBS & Fly ash & Silica sand \\
\hline $\mathrm{CaO}$ & 63.8 & 0.1 & 40 & 2.38 & -- \\
$\mathrm{SiO}_{2}$ & 19.9 & 92 & 35 & 59 & 99.73 \\
$\mathrm{Al}_{2} \mathrm{O}_{3}$ & 4.8 & 0.7 & 12 & 23 & 0.1 \\
$\mathrm{Fe}_{2} \mathrm{O}_{3}$ & 3.1 & 0.8 & 0.2 & 8.8 & 0.05 \\
$\mathrm{MgO}_{\mathrm{SO}}$ & 1.1 & -- & 10 & 1.39 & 1.0 \\
$\mathrm{Na}_{2} \mathrm{O}$ & 3.3 & -- & -- & 0.27 & -- \\
$\mathrm{K}_{2} \mathrm{O}$ & 0.7 & 0.33 & -- & 0.74 & $<0.05$ \\
$\mathrm{~L} . \mathrm{O} . \mathrm{I}$ & 0.6 & 1.45 & -- & 2.81 & 0.01 \\
Specific gravity & 2.7 & 4.6 & 2.8 & 1.61 & 0.09 \\
Specific surface area $\left(\mathrm{mm}^{2}\right)$ & 3.18 & 2.20 & 2.90 & 2.20 & 2.6 \\
Mean particle size $(\mu \mathrm{m})$ & -- & $15-30$ & -- & -- & -- \\
\hline
\end{tabular}




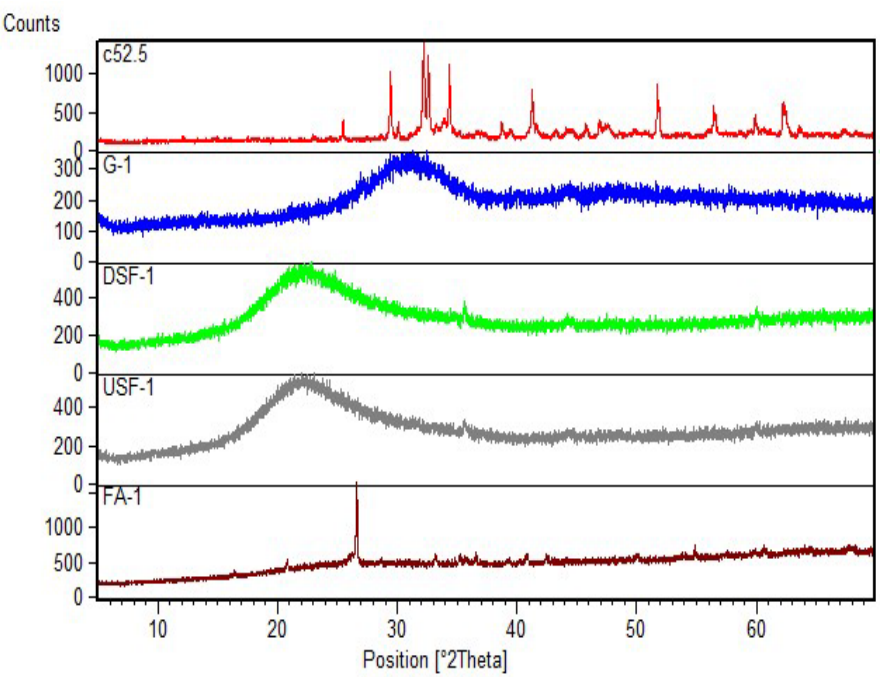

C52.5: High strength cement type CEM 52.5N

G-1: Ground-granulated blastfurnace slag (GGBS)

DSF-1: Densified silica fume (DSF)

UDSF-1: Undensified silica fume (UDSF)

FA-1: Fly ash (class S)

Figure 1. X-Ray patterns of cement and SCMs.

\subsection{Mix proportions}

Several mixes were designed to achieve the desired compressive strengths of highstrength mortar.

The absolute volume method was applied to determine the proportions of the cement, aggregates, superplasticizer, and water [2].

The designed quantities by mass of the constituent materials for the cubic meter were determined according to the following equation:

$$
\frac{C}{1000 \times \rho_{C}}+\frac{S . S}{1000 \times \rho_{S . S}}+\frac{S . P}{1000 \times \rho_{S . P}}+\frac{W}{1000}=1.0
$$

Where: C, S.S, S.P and W are the amount of cement, silica sand, superplasticizer and water in $\mathrm{kg}$, respectively, $\rho_{C}, \rho_{S . S}$ and $\rho_{S . P}$ is the specific gravity of cement, silica sand and superplasticizer, respectively.

After establishing the mix proportions of the control mix, 26 mixes that contain SCMs were designed. In these mixes, all the mix proportions of the control mix were kept constant except the amount of cement and the SCMs.

The SCMs were included in the control high-strength mortar mix as a volumetric replacement of cement according to equation (1), as listed in Table 2.

The absolute volume method was adopted in the calculation of the mix proportions of the mix. The mixing procedure included firstly dry mixing for about 5 minutes of cementitious materials (cement and SCMs) then added silica sand. After that, during mixing, the water which previously mixed with the superplasticizer was added, and the mixing was continued for 10 minutes.

The designed mixes included three main groups. The first group comprised a single replacement of each SCMs with three replacement ratios, $10 \%, 20 \%$, and $30 \%$ of cement. Another replacement ratio of $40 \%$ was investigated for GGBS based on the observed enhancement of the literature review.

The investigated replacement for binary replacements were $5 \%$ GGBS+5\% SCM, $10 \%$ GGBS+10\%SCM and 15\% GGBS+15\% SCM. The ternary replacement included $5 \%$ and $10 \%$ of each type of SCMs. 
Table 2

Mix proportions of ultra-high strength mortar including SCMs

\begin{tabular}{|c|c|c|c|c|c|c|c|c|}
\hline Mix & $\begin{array}{c}\mathrm{C} \\
\left(\mathrm{kg} / \mathrm{m}^{3}\right)\end{array}$ & $\begin{array}{c}\mathrm{S} . \mathrm{S} \\
\left(\mathrm{kg} / \mathrm{m}^{3}\right)\end{array}$ & $\begin{array}{c}W \\
\left(\mathrm{~kg} / \mathrm{m}^{3}\right)\end{array}$ & $\begin{array}{c}\text { S.P } \\
\left(\mathrm{kg} / \mathrm{m}^{3}\right)\end{array}$ & $\begin{array}{c}\text { GGBS } \\
\left(\mathrm{kg} / \mathrm{m}^{3}\right)\end{array}$ & $\begin{array}{c}\text { DSF } \\
\left(\mathrm{kg} / \mathrm{m}^{3}\right)\end{array}$ & $\begin{array}{l}\text { UDSF } \\
\left(\mathrm{kg} / \mathrm{m}^{3}\right)\end{array}$ & $\begin{array}{c}\text { FA } \\
\left(\mathrm{kg} / \mathrm{m}^{3}\right)\end{array}$ \\
\hline Control (M105) & 1100 & 1100 & 200 & 30 & -- & -- & -- & -- \\
\hline 10 GGBS & 990 & 1100 & 200 & 30 & 100 & -- & -- & -- \\
\hline 20 GGBS & 880 & 1100 & 200 & 30 & 200 & -- & -- & -- \\
\hline 30 GGBS & 770 & 1100 & 200 & 30 & 300 & -- & -- & -- \\
\hline 40 GGBS & 660 & 1100 & 200 & 30 & 400 & -- & -- & -- \\
\hline 10 DSF & 990 & 1100 & 200 & 30 & -- & 76 & -- & -- \\
\hline 20 DSF & 880 & 1100 & 200 & 30 & -- & 152 & -- & -- \\
\hline 30 DSF & 770 & 1100 & 200 & 30 & -- & 228 & -- & -- \\
\hline 10 USF & 990 & 1100 & 200 & 30 & -- & -- & 76 & -- \\
\hline 20 USF & 880 & 1100 & 200 & 30 & -- & -- & 152 & -- \\
\hline 30 USF & 770 & 1100 & 200 & 30 & -- & -- & 228 & -- \\
\hline $10 \mathrm{FA}$ & 990 & 1100 & 200 & 30 & -- & -- & -- & 76 \\
\hline $20 \mathrm{FA}$ & 880 & 1100 & 200 & 30 & -- & -- & -- & 152 \\
\hline $30 \mathrm{FA}$ & 770 & 1100 & 200 & 30 & -- & -- & -- & 228 \\
\hline $5 G G B S+5 D S F$ & 990 & 1100 & 200 & 30 & 51 & 39 & -- & -- \\
\hline 10GGBS+10DSF & 880 & 1100 & 200 & 30 & 102 & 78 & -- & -- \\
\hline 15GGBS+15DSF & 770 & 1100 & 200 & 30 & 153 & 117 & -- & -- \\
\hline $5 G G B S+5 U D S F$ & 990 & 1100 & 200 & 30 & 51 & -- & 39 & -- \\
\hline 10GGBS+10UDSF & 880 & 1100 & 200 & 30 & 102 & -- & 78 & -- \\
\hline 15GGBS+15UDSF & 770 & 1100 & 200 & 30 & 153 & -- & 117 & -- \\
\hline $5 G G B S+5 F A$ & 990 & 1100 & 200 & 30 & 51 & -- & -- & 39 \\
\hline 10GGBS+10FA & 880 & 1100 & 200 & 30 & 102 & -- & -- & 78 \\
\hline 15GGBS+15 FA & 770 & 1100 & 200 & 30 & 153 & -- & -- & 117 \\
\hline $5 G G B S+5 D S F+5 F A$ & 935 & 1100 & 200 & 30 & 51 & 39 & -- & 39 \\
\hline 10GGBS+10DSF+10FA & 770 & 1100 & 200 & 30 & 102 & 78 & -- & 78 \\
\hline $5 G G B S+5 U D S F+5 F A$ & 935 & 1100 & 200 & 30 & 51 & -- & 39 & 39 \\
\hline 10GGBS+10UDSF+10FA & 770 & 1100 & 200 & 30 & 102 & -- & 78 & 78 \\
\hline
\end{tabular}

C : cement, S.S: silica sand, W: water, S.P: superplasticizer, GGBS: ground granulated blast furnace slag, DSF: densified silica fume, UDSF: undensified silica fume, FA: fly ash.

\subsection{Test methods}

\subsubsection{Workability}

Flowability of the fresh cementitious material is an essential property to assure compatible mixing, casting, and adequate consolidation as a homogenous mass.

The amount of water within the mix has a crucial role in controlling workability.

A large amount of water improves the workability but impairs the strength by increasing the voids inside the hardened mortar. In addition, the presence of voids reduces the durability by increasing the gas and liquid permeability of the hardened structure. In this research, the workability of the mortar was measured using the flow table test based on the BS-EN 1015-3:1999 [35], as shown in Figure 2. 

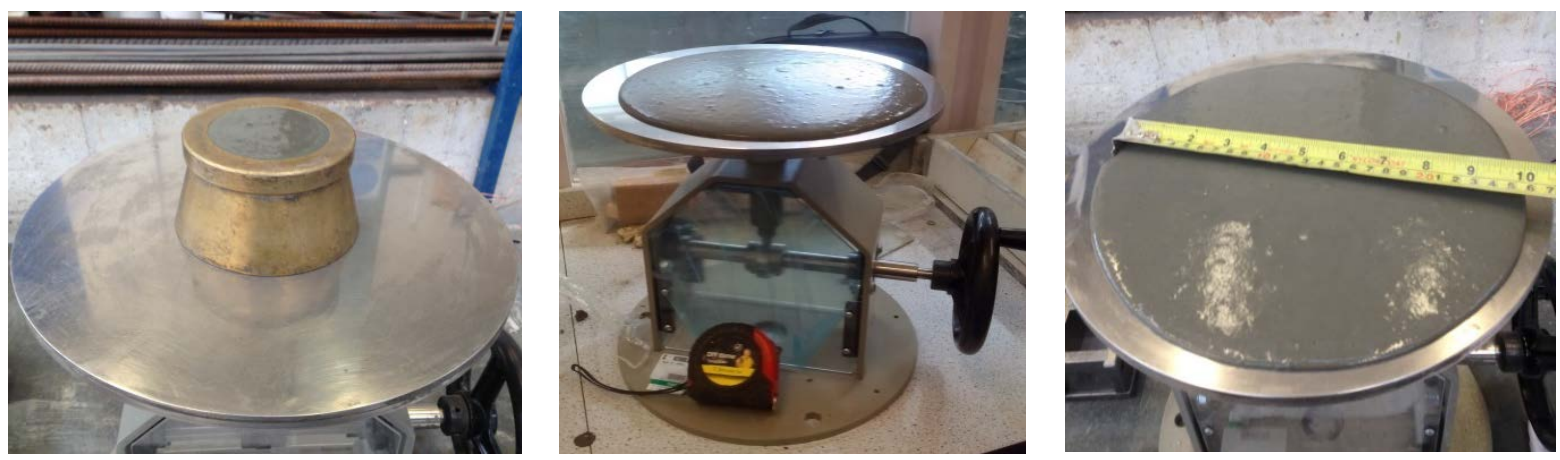

Figure 2. Flow table test setup of high strength fresh mortar.

\subsubsection{Compressive and tensile strength}

Usually, a compressive strength test was used to explore the behaviour of materials under compressive stresses. This behaviour is essential to gain an inclusive picture of the quality of mortar because the strength of mortar is directly related to the structure of the hydrated cement [2]. Compressive strength tests at ages 7, 28, and 90 days were carried out for cube mortar samples with dimensions $50 \times 50 \times 50 \mathrm{~mm}$ based on BS EN 12390-3:2009 [36]. Three specimens of each mix were tested, and the average strength was reported. A universal testing machine was used based on a constant rate of displacement-based loading of 0.01 $\mathrm{mm} / \mathrm{sec}$, as shown in Figure 3.a.

The tensile strength of mortar is also vital in determining the load causing the cracking of the hardened mortar. The tensile strength of the hardened structure is controlled by the chemical adhesion bond between the results of cement hydration and the aggregates [2]. A direct tensile test of three dog bone specimens of each mix was implemented to determine the effect of SCMs on the tensile strength of high strength mortar (HSM). The dog bone specimen has $78 \mathrm{~mm}$ length and $25.5 \times 25.5 \mathrm{~mm}^{2}$ cross sectional area at the midspan. A universal testing machine with a rate of displacement-based loading of $0.02 \mathrm{~mm} / \mathrm{sec}$ was used, as shown in Figure 3.b.

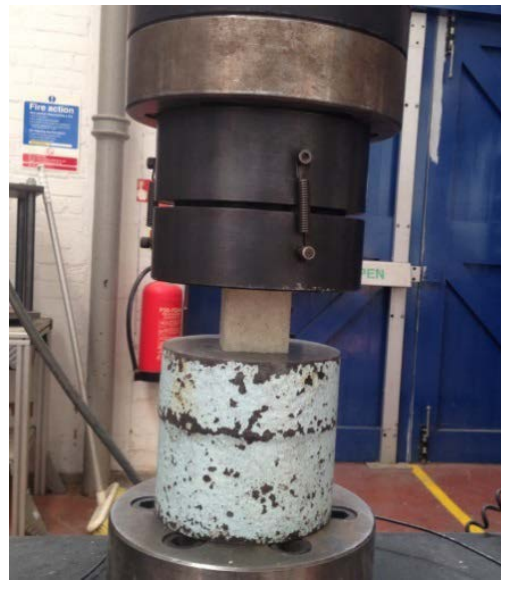

a)

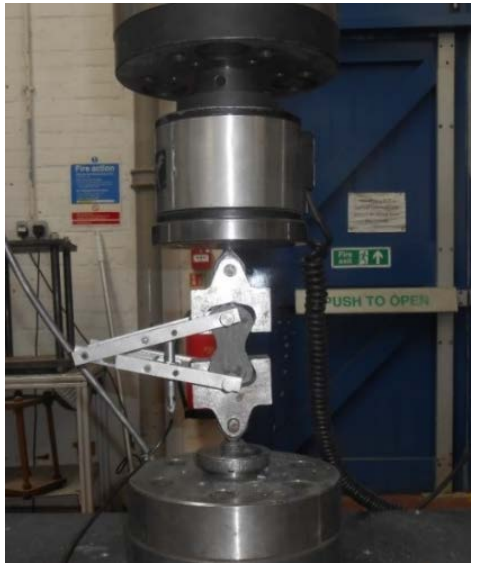

b)

Figure 3. a) Compression test setup, b) tensile test setup of mortars.

\subsubsection{X-RD patterns}

To analysis the composition of the main components of the mortar matrix, an X-ray diffraction test of powder samples was performed using an X'Pert diffractometer with CuK 
radiation $(\lambda=1.5418 \mathrm{~A})$ operating at $40 \mathrm{kV}, 30 \mathrm{~mA}$. This test is adopted to identify the variation of the amount of calcium hydroxide $\left(\mathrm{Ca}(\mathrm{OH})_{2}\right)$ in the sample. The $\mathrm{Ca}(\mathrm{OH})_{2}$ variation demonstrates the reactions between the SCMs with the $\mathrm{Ca}(\mathrm{OH})_{2}$ to produce supplementary $\mathrm{C}-\mathrm{S}-\mathrm{H}$. The peaks at $2 \theta$ equal to $34^{\circ}$ were adopted to refer to the amount of $\mathrm{Ca}(\mathrm{OH})_{2}$ based on previous studies $[11,14,28,36]$. The test includes preparing a powder of the sample that tested under compression load at 28 days and then measures the reflection of the X-ray. The results of the test were analysed using the provided software with the $\mathrm{X}$-ray machine.

\section{Results and discussion}

\subsection{Influence of SCMs on the workability}

The effect of the addition SCMs on the workability of high-strength mortar (HSM) is demonstrated in Figure 4. Single replacements of all replacement ratios of GGBS and FA displayed higher workability as the replacement ratio increases. The effectiveness of GGBS in improving the workability was due to the surface characteristics of the GGBS particles, which are smooth and absorb little water during mixing [2]. Similarly, most FA particles are spherical and solid which reduces the water demand for a particular workability [2]. Megat Johari et al. (2011) [11] reported a similar observation of enhancing the workability of FA and GGBS with high-strength concrete. In the same field, Dave et al. (2017) [30] observed that the addition of FA was significantly increasing the workability of concrete.

In contrast, mixes with DSF and UDSF explained a reduction in workability. That could be attributed to the particles patterns of silica fume which have a high surface area that absorbs a high amount of water during mixing, which led to increasing the water demand of the mix. A similar reduction in workability due to silica fume was observed by previous studies $[5,7,8]$. However, in binary replacement, the addition of GGBS combined with DSF enhanced the workability for all replacement ratios. Similarly, to less extent, the workability of mortar with UDSF increased as the replacement ratio increased in the presence of GGBS. However, the addition of GGBS with FA reduced the workability comparing with the single replacement of FA counterparts. The workability of ternary replacements of all ratios proportional increasingly with the replacement ratios. Also, it can be observed that mixes with SCMs contain UDSF explained higher workability than DSF counterparts. These results agree with the findings observed by Dave et al. (2017) [30].

In summary, the results demonstrated the effectiveness of addition GGBS in improving the workability of mortar in all forms of replacements (single, binary and ternary). Moreover, regardless of the type and amount of SCMs replacement, binary and ternary replacement explained a higher enhancement of the workability of high-strength mortar.
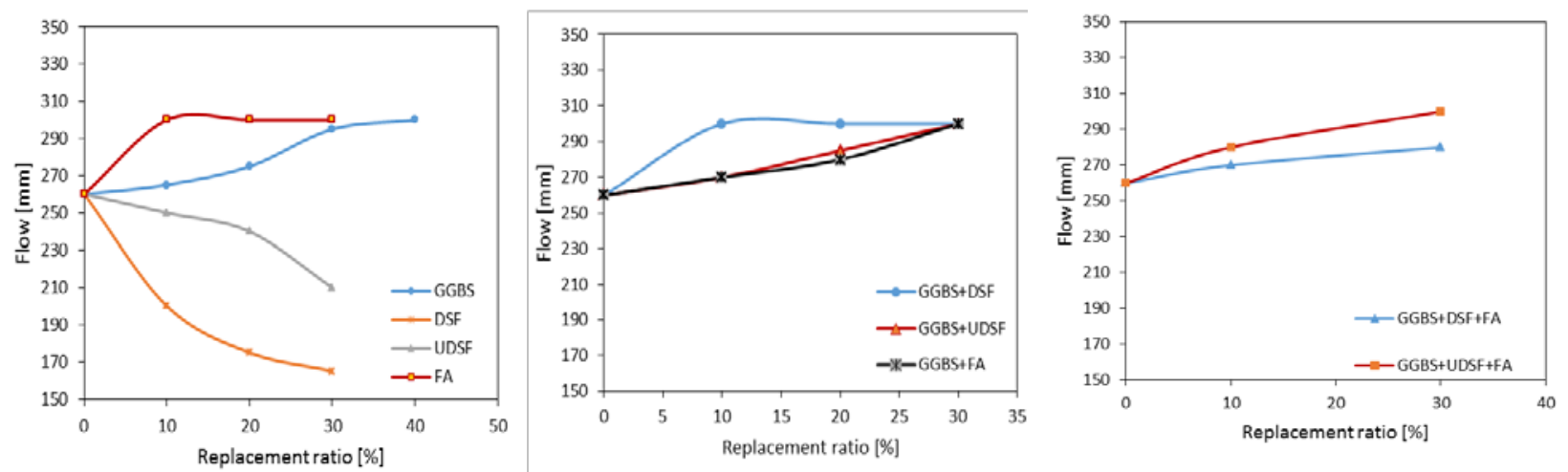

Figure 4. Effect of SCMs replacements of on workability of HSM. 


\subsection{Influence of SCMs on the compressive strength}

Figure 5 demonstrates the enhancement in the compressive strength for 28 days age respecting to the control mix (M105). The obtained compressive strength at all ages increased comparing with the control mortar for all mixes with $10 \%$ of single replacement of all types of SCMs as illustrated in Figure 6. However, the enhancement was continued for GGBS and UDSF up to a $20 \%$ replacement ratio and a reduction in the enhancement was observed for higher single replacement. At 28 days, the compressive strength was increased to about $28 \%$ comparing with the control mix. The highest compressive strength was observed for $20 \%$ of UDSF, while the lowest strength was found for the $30 \%$ replacement ratio of densified silica fume. That may be due to the low workability of mixes with DSF, which leads to a decrease in the compaction of the mix during casting, see Figure 4. The results also explained that mixes with a single replacement of GGBS explained higher compressive strength than mixes with FA despite both pozzolanic materials improve the workability. That could be because most of the silica in the mineral composition of FA has a crystalline structure as observed in the X-Ray patterns.

Figure 7 illustrates the variation of the effect of binary replacement of SCMs. The compressive strength at 28 days ranged between 92.2MPa and 135.2MPa. The GGBS and UDSF explained the highest compressive strength comparing to other SCMs. In addition, it was observed increasing in compressive strength as the replacement ratio increased. However, the compressive strength of binary replacement consists of $5 \%$ GGBS, and $5 \%$ DSF explained better performance than binary replacement of UDSF. That may be due to the higher reactivity of densified silica fume, which led to rapid consumption of the available $\mathrm{Ca}(\mathrm{OH})_{2}$. This assumption can be proven by the results at the age of 90 days. All replacement ratios of binary replacement of GGBS and DSF explained the same compressive strength due to the availability of $\mathrm{Ca}(\mathrm{OH})_{2}$ as a result of cement hydration. Binary replacement of FA was ineffective on the compressive strength at the initial stage, and compressive strength was lower than control beams. At 90 days, binary replacement of GGBS and FA up to $20 \%$ improved the compressive strength compared to the control mix. The reason could be due to the availability of $\mathrm{Ca}(\mathrm{OH})_{2}$ that is required for the pozzolanic reaction which is agreed by literature findings [30,37]. Overall, it can be stated that the enhancement of binary replacements of SCMs was higher than single replacement which is compatible with the observation of Gesoglu et al. (2009).

The effect of ternary replacements is illustrated in Figure 8. Ternary replacement of GGBS, DSF, and FA at initial stages exhibited negligible enhancement, but at 90 days the enhancement was obvious. $5 \%$ of UDSF increases the compressive strength, while $10 \%$ reduced the strength for all ages. That may be due to the segregation of mixed components which can be noted from the high workability (flow excess $300 \mathrm{~mm}$ ). This segregation refers to a high content of fluids that leaving voids in the hardened structure of mortar [2]. The compressive strength at 28 days of the ternary replacements ranged between $93.5 \mathrm{MPa}$ and $119.6 \mathrm{MPa}$, which indicates that binary replacement is more effective, and these results agree with the findings of Gesoglu et al. (2009) [20]. 


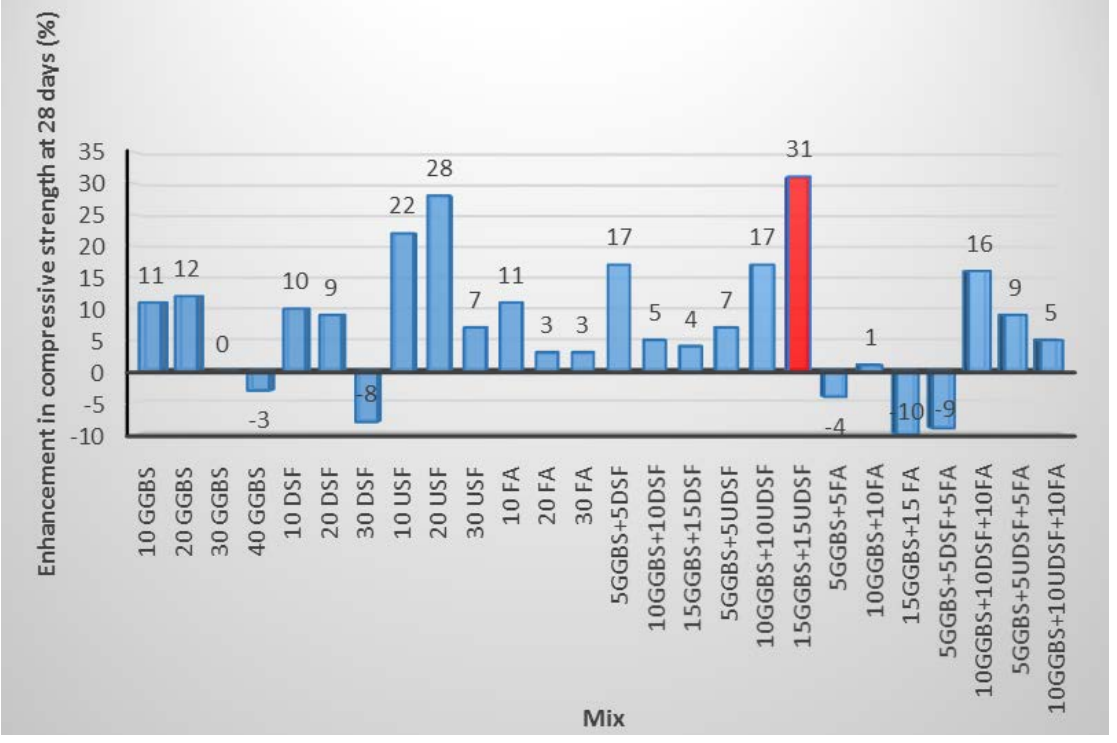

Figure 5. Effect of SCMs on compressive strength of HSM.
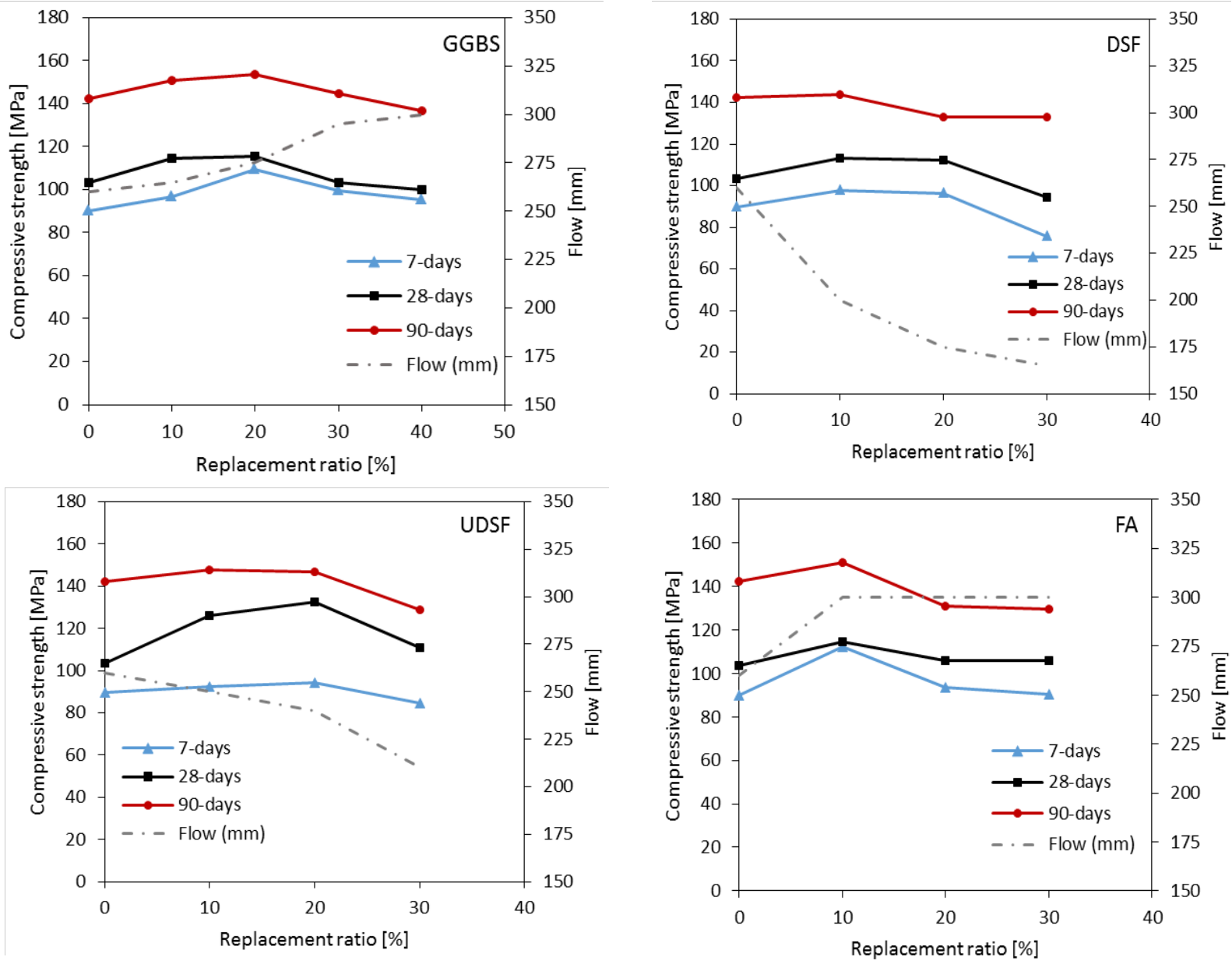

Figure 6. Effect of single replacement of SCMs on compressive strength of HSM. 

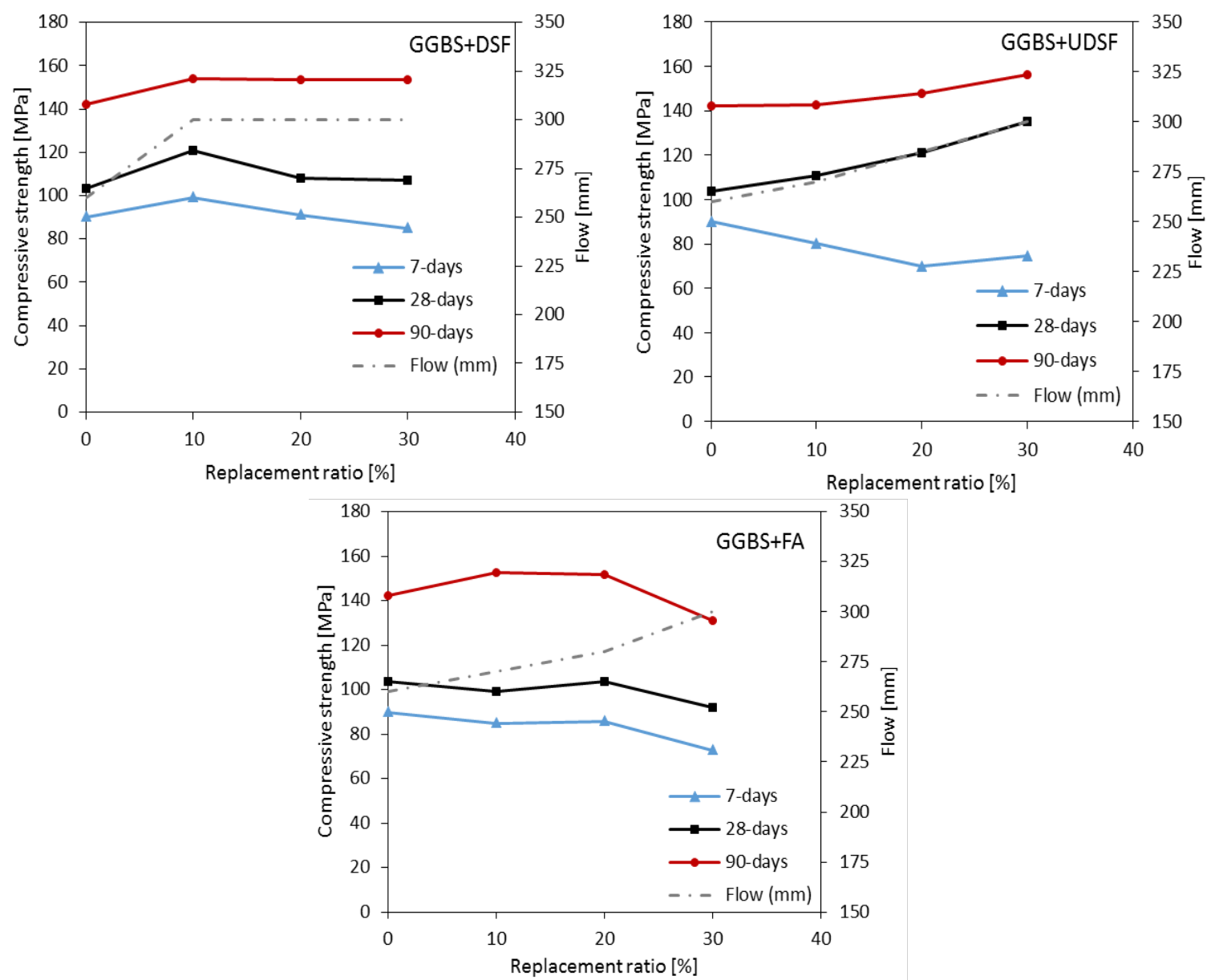

Figure 7. Effect of binary replacement of SCMs on compressive strength of HSM.
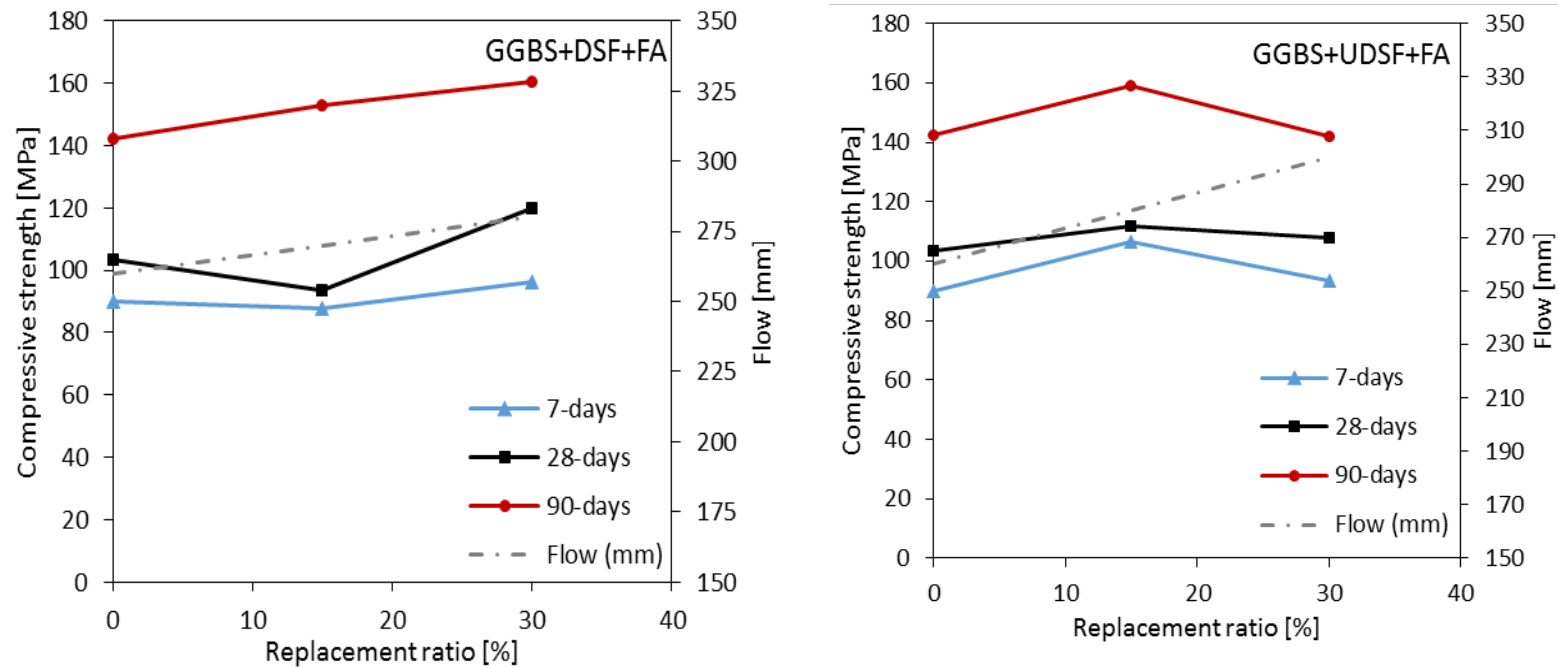

Figure 8. Effect of ternary replacement of SCMs on compressive strength of HSM.

\subsection{Influence of SCMs on the tensile strength}

The single replacement explained the disadvantage of addition GGBS and FA on the tensile strength as shown in Figure 8. However, the addition of UDSF and DSF improves the tensile strength, which could be attributed to the lower silica content of FA and GGBS. A similar reduction was observed by Dave et al. (2017) [30] with 30\% replacement of FA. The single replacements of SCMs explained tensile strength ranged between $4.3 \mathrm{MPa}$ and $6.7 \mathrm{MPa}$ depending on the type of SCMs. The UDSF exhibited a continuous increase in tensile strength 
for all replacement rations. However, DSF presented an optimum replacement ratio of $10 \%$ which could be due to a decrease in the compactness of the mix as a result of reducing the flowability of mixes.

The best performance was observed for binary with tensile strength ranged between 5.3 $\mathrm{MPa}$ and 6.7 MPa. The maximum tensile strength was reported for a replacement ratio of 15\% GGBS and 15\% UDSF with 6.7 MPa. The lowest tensile strength was found for binary replacement of GGBS and FA. That could be because of less silica in the chemical composition of FA in comparison with silica fume.

Figure 9 demonstrated a negligible effect of DSF and FA in enhancing the tensile strength. However, UDSF exhibited enhancement in the tensile strength with a replacement ratio equal to $15 \%$. Above this replacement ratio, a reduction in tensile strength was observed. The tensile strength of ternary replacements mixes was ranged between $4.5 \mathrm{MPa}$ and 6.3MPa which explains less effectiveness comparing to binary replacement.
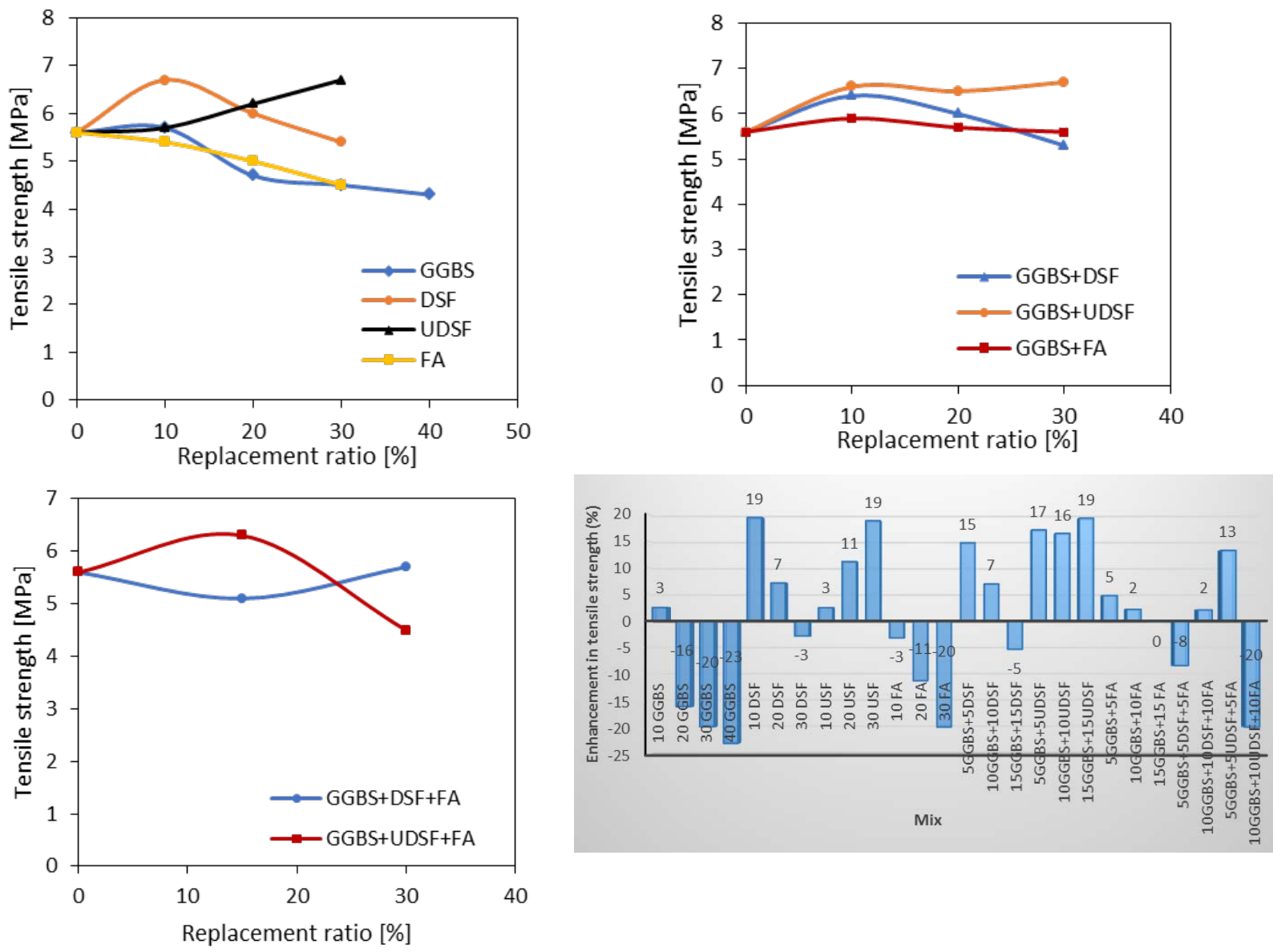

Figure 9. Effect of SCMs replacement on tensile strength of HSM.

Figure 10 demonstrates a consistency of the general behaviour between the tensile and compressive strength of high-strength mortar with SCMs. However, there is no direct proportionality between the two types of strength. In addition, in some cases, particularly of high replacement ratio, the increase in compressive strength did not accompany with increasing in tensile strength. That could be due to the lack of calcium hydroxide for a high replacement ratio, and the SCM works as a filler rather than cementitious material. That will be effective in resisting the compressive stresses by friction, while it has a negligible 
influence in resisting the tensile stresses. The figure also indicated the superiority of binary replacements among single and ternary replacements.

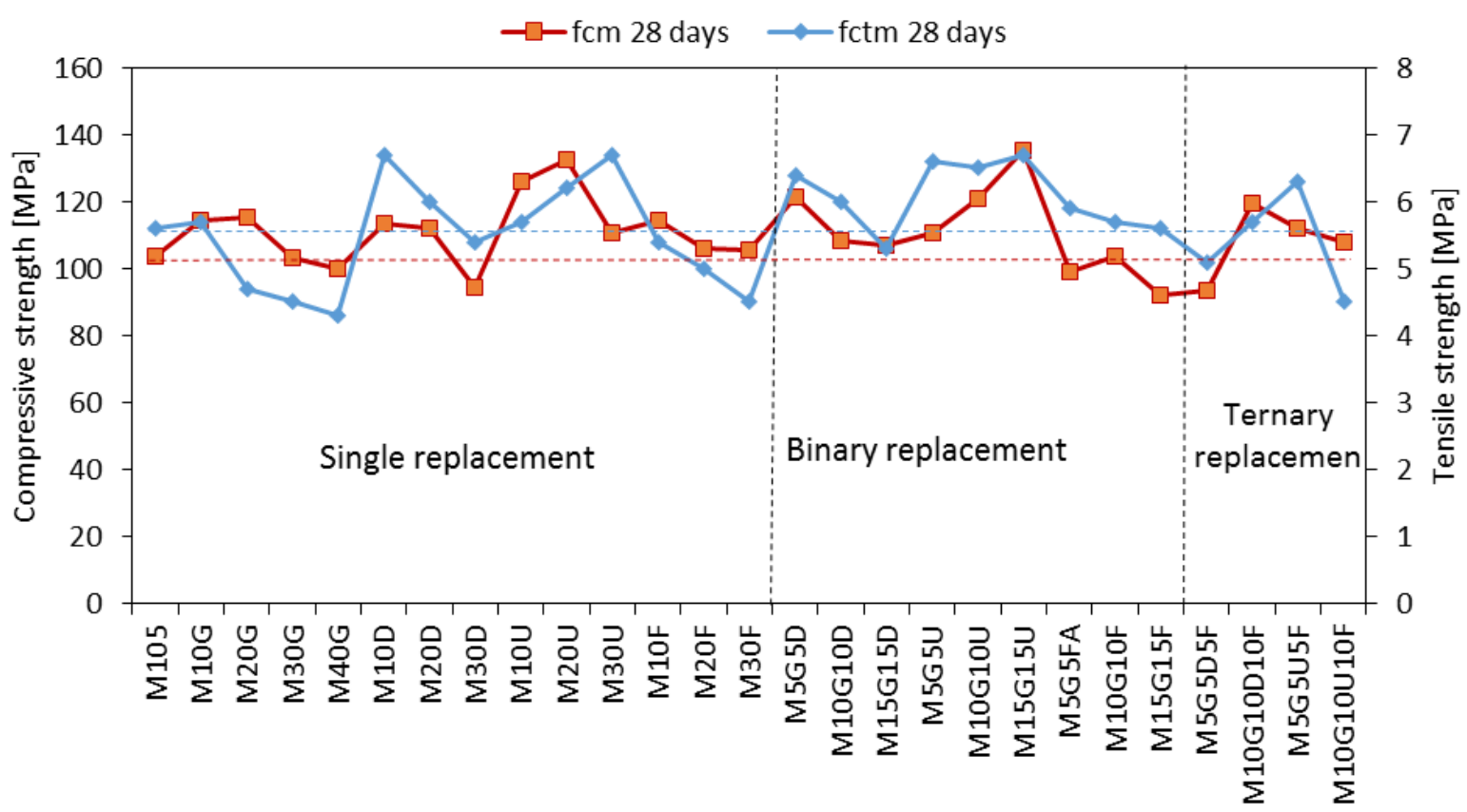

Figure 10. Mechanical properties of single, binary and ternary replacement of SCMs.

\subsection{XRD patterns}

Figure 11 presents the intensity peaks of $\mathrm{Ca}(\mathrm{OH})_{2}$ obtained from the analysis of the XRay diffraction test of high strength mortar with SCMs. As shown in the figure, the SCMs reduced the amount of calcium hydroxide for control mix (M105). This reduction increased as the replacement ratio increases which indicates to the consumption of calcium hydroxide in the pozzolanic reaction of SCMs. The results also demonstrated higher content of amorphous $\mathrm{SiO}_{2}$, such as DSF and UDSF were more effective in contributing the pozzolanic reaction products which present higher strength enhancement. These findings consistent with the observation of Supit et al. (2014) [28].

High consistency between the obtained compressive strength and the intensity peaks of $\mathrm{Ca}(\mathrm{OH})_{2}$ was observed. For the same replacement ratio, as the intensity peaks decrease, the compressive strength increases. However, the addition of DSF with replacement ratio $20 \%$ and $30 \%$ exhibited a reduction in intensity peaks of $\mathrm{Ca}(\mathrm{OH})_{2}$ without a considerable contribution to the strength. That could be attributed to the low flowability of the matrix, which in turns decrease the compaction of the mix during casting and increase the voids inside the hardened mortar.

The best performance in consumption $\mathrm{Ca}(\mathrm{OH})_{2}$ was observed for mixes UDSF because of the high content of amorphous $\mathrm{SiO}_{2}$. In contrast, mixes contain fly ash explained the highest intensity peaks of $\mathrm{Ca}(\mathrm{OH})_{2}$ among all SCMs mixes. That stated the low compressive strength that was observed of mortar with FA in comparison with control mortar.

Overall, binary replacement of 15\% GGBS and 15\% UDSF explained the lowest intensity peak of $\mathrm{Ca}(\mathrm{OH})_{2}$ which refers to high activity in the pozzolanic reaction that led to enhance the strength of mortar. This finding coincides with the highest compressive and tensile strength of this mix proportion. 


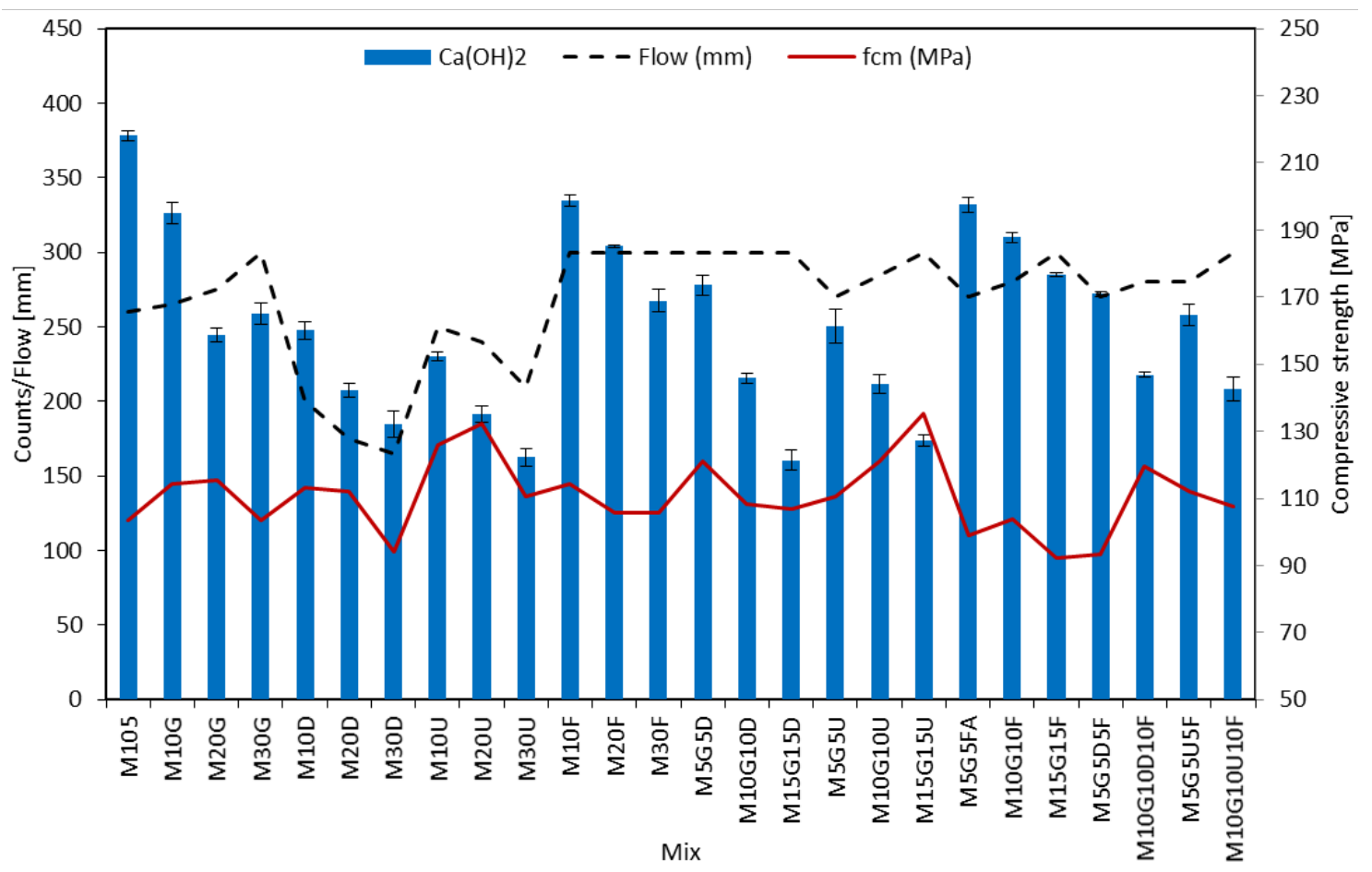

Figure 11. XRD of calcium hydroxide peaks of HSM with SCMs.

\section{Conclusions}

Based on the result of the investigated SCMs, the following conclusions can be drawn:

- Apart from both types of silica fume, all replacement of the SCMs improved the workability of the fresh mixes depending on the type and ratio of replacement. In addition, the most considerable improvement in workability was observed for mixes with fly ash.

- Both types of silica fume reduced the workability of mortar. However, the un-densified form explained better fresh mortar properties.

- Fly ash demonstrated a relatively low enhancement in the mechanical properties of high strength mortar compared with other SCMs.

- Regarding the mechanical properties, both types of silica fume exhibited approximately similar behaviour up to $10 \%$ replacement. Higher replacement indicated the superiority of unidentified silica fume in increasing the strength.

- GGBS explained enhancement in workability as well as in the mechanical properties.

- Binary replacement of $15 \%$ of un-densified silica fume and $15 \%$ of GGBS presented the highest mechanical properties. Moreover, the effect of enhancing the strength of mortar was evident from the low intensity of the $\mathrm{Ca}(\mathrm{OH})_{2}$ that determined from the XRay diffraction analysis compared with mixes with lower strength.

- Despite of the obvious consistency between the compressive and tensile strength, a direct relationship between them is unavailable due to the variation in the hardened structure on mortar due to flowability. 
Acknowledgements: The author would like to thank the University of Brighton for providing the required equipment for the investigation. Thank is also continued to the Elkem A Bluestar Company and Hanson UK Company for supplying the SCMs.

\section{References}

1. Ernst Worrell, Lynn Price, Nathan Martin, CHRIS HENDRIKS \& MEIDA, L. O. 2001. Carbon dioxide emissions from the global cement industry. Annual Review of Energy and the Environment, 26, $303-329$.

2. Neville A.M. 2011. Properties of concrete, Edinburgh Gate Harlow Essex, Pearson Education Limited.

3. Mazloom M., Ramezanianpour A. A. \& Brooks J. J. 2004. Effect of silica fume on mechanical properties of highstrength concrete. Cement and Concrete Composites, 26, 347-357.

4. Megat Johari M. A., Brooks J. J., Kabir S. \& Rivard p. 2011. Influence of supplementary cementitious materials on engineering properties of high strength concrete. Construction and Building Materials, 25, 2639 - 2648.

5. Inan Sezer G. 2012. Compressive strength and sulfate resistance of limestone and/or silica fume mortars. Construction and Building Materials, 26, 613 - 618.

6. Bagheri A. R., Zanganeh H. \& Moalemi M. M. 2012. Mechanical and durability properties of ternary concretes containing silica fume and low reactivity blast furnace slag. Cement and Concrete Composites, 34, 663 - 670.

7. Bagheri A., Zanganeh H., Alizadeh H., Shakerinia M. \& Marian M. A. S. 2013. Comparing the performance of fine fly ash and silica fume in enhancing the properties of concretes containing fly ash. Construction and Building Materials, 47, 1402 - 1408.

8. Jalal M., Pouladkhan A., Harandi O. F. \& Jafari D. 2015. Comparative study on effects of Class F fly ash, nano silica and silica fume on properties of high performance self compacting concrete. Construction and Building Materials, 94, 90 - 104.

9. Hossain M. M., Karim M. R., Hasan M., Hossain M. K. \& Zain M. F. M. 2016. Durability of mortar and concrete made up of pozzolans as a partial replacement of cement: A review. Construction and Building Materials, 116, $128-140$.

10. Elahi A., Basheer P. A. M., Nanukuttan S. V. \& Khan Q. U. Z. 2010. Mechanical and durability properties of high performance concretes containing supplementary cementitious materials. Construction and Building Materials, 24, 292 - 299.

11. Seleem H. E.-D. H., Rashad A. M. \& El-Sabbagh B. A. 2010. Durability and strength evaluation of highperformance concrete in marine structures. Construction and Building Materials, 24, 878 - 884.

12. Megat Johari M. A., Brooks J. J., Kabir S. \& Rivard P. 2011. Influence of supplementary cementitious materials on engineering properties of high strength concrete. Construction and Building Materials, 25, 2639-2648.

13. Barnett S. J., Soutsos M. N., Millard S. G. \& Bungey J. H. 2006. Strength development of mortars containing ground granulated blast-furnace slag: Effect of curing temperature and determination of apparent activation energies. Cement and Concrete Research, 36, 434 - 440.

14. Alhozaimy A., Al-Negheimish A., Alawad O. A., Jaafar M. S. \& Noorzaei J. 2012. Binary and ternary effects of ground dune sand and blast furnace slag on the compressive strength of mortar. Cement and Concrete Composites, 34, 734 - 738.

15. Li K., Zeng Q., Luo M. \& Pang X. 2014. Effect of self-desiccation on the pore structure of paste and mortar incorporating 70\% GGBS. Construction and Building Materials, 51, 329 - 337.

16. Zhang W., Hama Y. \& Na S. H. 2015. Drying shrinkage and microstructure characteristics of mortar incorporating ground granulated blast furnace slag and shrinkage reducing admixture. Construction and Building Materials, 93, 267 - 277.

17. Özbay E., Erdemir M. \& Durmuş H. İ. 2016. Utilization and efficiency of ground granulated blast furnace slag on concrete properties - A review. Construction and Building Materials, 105, 423 - 434.

18. Mardani-Aghabaglou A., Inan Sezer G. \& Ramyar K. 2014. Comparison of fly ash, silica fume and metakaolin from mechanical properties and durability performance of mortar mixtures view point. Construction and Building Materials, 70, 17 - 25.

19. Canpolat F. 2012. Sulfate resistance of mortars containing silica fume and pozzolan. Proceedings of the Institution of Civil Engineers - Construction Materials, 165, 65 - 72.

20. Gesoğlu M., Güneyisi E. \& Özbay E. 2009. Properties of self-compacting concretes made with binary, ternary, and quaternary cementitious blends of fly ash, blast furnace slag, and silica fume. Construction and Building Materials, 23, 1847 - 1854.

21. Zelić J., Krstulović R., Tkalčec E. \& Krolo P. 2000. The properties of Portland cement-limestone-silica fume mortars. Cement and Concrete Research, 30, 145 - 152. 
22. Qing Y., Zenan Z., Deyu K. \& Rongshen C. 2007. Influence of nano-SiO ${ }_{2}$ addition on properties of hardened cement paste as compared with silica fume. Construction and Building Materials, 21, 539 - 545.

23. Zhang Z., Zhang B. \& Yan P. 2016a. Hydration and microstructures of concrete containing raw or densified silica fume at different curing temperatures. Construction and Building Materials, 121, 483 - 490.

24. Borosnyói A. 2016. Long term durability performance and mechanical properties of high performance concretes with combined use of supplementary cementing materials. Construction and Building Materials, $112,307-324$.

25. Zhang Z., Zhang B. \& Yan P. 2016b. Comparative study of effect of raw and densified silica fume in the paste, mortar and concrete. Construction and Building Materials, 105, 82-93.

26. Motahari Karein S. M., Ramezanianpour A. A., Ebadi T., Isapour S. \& Karakouzian M. 2017. A new approach for application of silica fume in concrete: Wet granulation. Construction and Building Materials, 157, 573 581.

27. Wongkeo W., Thongsanitgarn P. \& Chaipanich A. 2012. Compressive strength and drying shrinkage of fly ash-bottom ash-silica fume multi-blended cement mortars. Materials \& Design (1980 - 2015), 36, $655-662$.

28. Supit S. W. M., Shaikh F. U. A. \& Sarker P. K. 2014. Effect of ultrafine fly ash on mechanical properties of high volume fly ash mortar. Construction and Building Materials, 51, 278 - 286.

29. Rashad A. M., Seleem H. E.-D. H. \& Shaheen A. F. 2014. Effect of Silica Fume and Slag on Compressive Strength and Abrasion Resistance of HVFA Concrete. International Journal of Concrete Structures and Materials, 8, $69-81$.

30. Dave N., Misra A. K., Srivastava A., Sharma A. K. \& Kaushik S. K. 2017. Study on quaternary concrete microstructure, strength, durability considering the influence of multi-factors. Construction and Building Materials, 139, $447-457$.

31. BS EN 15167-1. 2006. Ground granulated blast furnace slag for use in concrete, mortar and grout.

32. Teng S., Lim T. Y. D. \& Sabet Divsholi B. 2013. Durability and mechanical properties of high strength concrete incorporating ultra fine Ground Granulated Blast-furnace Slag. Construction and Building Materials, 40, $875-881$.

33. BS EN 450-1. 2012. Fly ash for concrete. Definition, specifications and conformity criteria. London. BSI Standards Publication.

34. BS EN 12620. 2013. Aggregates for concrete. London. BSI Standards Publication.

35. BS EN 1015-3 .1999. Methods of test for mortar for masonry. Determination of consistence of fresh mortar (by flow table). London. BSI Standards Publication.

36. Liu S., Han W. \& Li Q. 2017. Hydration Properties of Ground Granulated Blast-Furnace Slag (GGBS) Under Different Hydration Environments. Materials Science, 23.

37. Yazici H. 2007. The effect of curing conditions on compressive strength of ultra high strength concrete with high volume mineral admixtures. Building and Environment, 42, 2083 - 2089. 